\section{WHY BOOKS ARE BOUGHT AND BORROWED}

David W. Lewis

Head of Research and Information Services

University of Connecticut Library Storrs

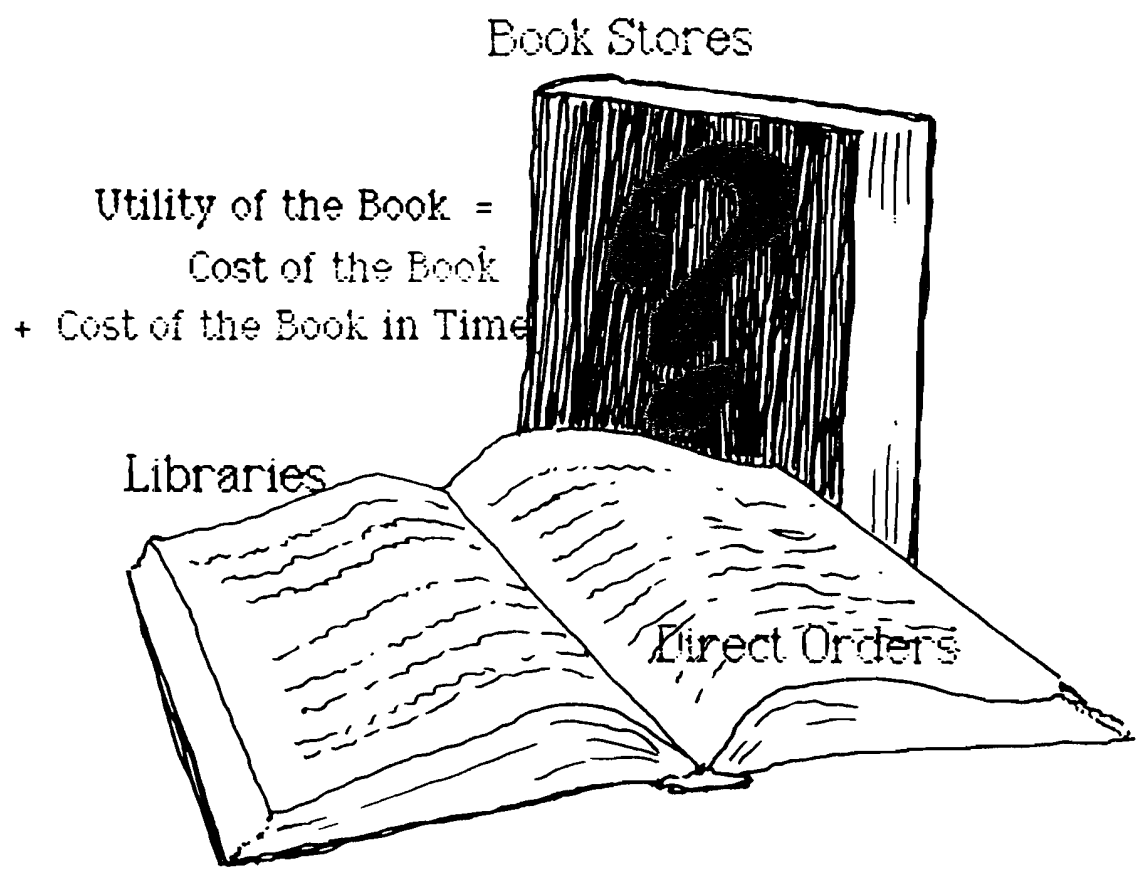

Books are among the most diverse products of our civilization. They combine a simple technology with the complexity of human thought to provide knowledge, insight, and entertainment. But little is known about why people use books the way they do. This article is a thought experiment, like Einstein's train, which will consider part of this question. It will develop a model of the costs to people when they buy or borrow books. The underlying premise is that librarians, booksellers, and publishers do not have a clear understanding of the costs - especially the cost of time-involved in using their services. Their successes tend to be the result of trial and error.

The model will begin with a person's desire to acquire a book. It will not consider why this desire exists; rather, it will explore the choices an individual has and how these compare to each other. As is the case whenever simple models are used to portray complex reality, much of the detail and texture will be lost, but in compensation we should be able to see relationships that would otherwise elude us.

The model will be constructed using an approach not often brought to bear on this topic. Although this approach and the related concepts may have a cold and calculated feel to those who see librarianship and the book trade as humanistic enterprises, it is my contention that looking at the issue from this perspective will provide insights that can make librarians, publishers, and booksellers better at what they do. The model was created using a Macintosh SE computer running the spreadsheet from Microsoft Works.

Utility and Cost

When we confront a choice, economists believe that we will choose the alternative that maximizes our utility. Utility is the concept used to represent the pleasure, satisfaction, or need fulfillment provided by an economic activity. To achieve this utility, we must pay some cost. This cost can have several forms, but the one most often considered is dollars. Others, like the cost of time or foregone opportunity, can also be significant. It is a fundamental precept of economic thinking that rational individuals will use whatever endowment they have to maximize their utility.

We will acquire books if the utility received from this activity is greater than any of the multitude of activities that we might otherwise engage in at the same cost. There will be some threshold past which the cost of acquiring books is not worth their utility. This threshold, of course, varies for individuals depending on their preferences, but the principle is the same for everyone. The relationship then is that the cost of an activity should equal the utility received from it. In our case:

Utility of the Book $=$ Cost of the Book 
This is a simple beginning from which we will construct a more complex picture. The first complicating factor is, as noted above, that cost is not only dollars. Since time is an important factor in the use of libraries and other means of acquiring books, we can then say:

Utility of the Book $=$ Cost of the Book in Dollars + Cost of the Book in Time

Clearly, while it is often possible to substitute time for money, and money for time, such substitution is not always possible. In some cases these limits are the result of constraints on the individual; in other cases they result from the possibilities the individual is offered. For example, libraries rarely offer their patrons an opportunity to pay to have a book sent to them; rather, patrons must go to the library and search out the book themselves.

A significant factor on both sides of our equation is uncertainty. A person who wants to acquire a book is rarely completely certain that the book will provide all the utility that is hoped for. This uncertainty can be reduced by recommendations from friends or reviewers.

On the other side, there is uncertainty to some degree about cost, especially of time. When I go to a book store or a library, I am investing time in a venture with an uncertain return. I may find the book that I am looking for, or one just as good, or I may not. This is not a trifling matter: some studies of the availability of material in academic libraries indicate that the chances of success are as low as 50 percent and are rarely better than 60 percent. It is also clear that most book stores carry only a small fraction of books available in print. My search for a book may end in failure.

When I go to the library it may take 15 minutes to find the book I want, or to ascertain that it is not now available, or it may take an hour or more. When I go to a book store I don't know if the book will be on the shelves or if I will have to wait two weeks or two months for a special order.

\section{The Model}

To set up the model, let's look at the decision to use a library as an example of the problems faced by one individual-we will call him John - in deciding whether to invest his time and money in searching for a book. Let's assume that, based on his experience, John knows that the chances are 75 percent that he will spend 15 minutes in his search of the library, and 25 percent that his search will take an hour, and assume that John's time is worth $\$ 10$ per hour. He also knows that, since there is a $\mathbf{5 0}$ percent chance that he will find the book, there is a 50 percent chance that he will not.

How will John assess the decision to go to the library? There are four possible outcomes: he could spend 15 minutes and find the book; spend 15 and not find the book; spend an hour and find the book; and spend an hour and not find the book. When the probabilities are added, the situation is as shown, below:

1. There is a 25 percent probability ( 50 percent chance that the search will be short times the 50 percent chance of success) that John will invest 15 minutes and find the book. His cost is $\$ 2.50$ and the return is the utility he places on borrowing the book

2. There is a 25 percent probability that John will invest 15 minutes and not find the book. Again, his cost is $\$ 2.50$, but the return is zero.

3 . There is a 25 percent probability that John will invest an hour and find the book. Again, his cost is $\$ 10$ and the return is the utility he places on borrowing the book.

4. There is a 25 percent probability that John will invest an hour and not find the book. Again, his cost is $\$ 10$, but the return is zero.

This means that, on average, John will invest $\$ 4.38$ worth of his time and will have a 50 percent chance of getting the book he wants. One implication of this analysis is that unless the book is worth $\$ 8.75$, John will not go to the library and search for it because even though on average John will invest only $\$ 4.38$, he will also on average have only a 50 percent rate of success. Half of the time he goes to the library he will receive no utility. The risk on a $\mathbf{5 0}$ percent chance of return requires that the payoff is worth twice this, or $\$ 8.75$. If the book is expected to provide more than $\$ 8.75$ in utility, John will go to the library. If the expectation is for utility of less than

$\$ 8.75$, John will spend his time doing something else.

This situation is probably not unusual, yet I suspect that many librarians would be surprised that the costs they are imposing on their users are so high.

\section{Variables in the Model}

The first important variable to consider is the value of the patron's time. If we use the same assumptions as we did above -50 percent success rate and 75 percent chance of a 15-minute search - with different values for the user's time, the utilities required to go to the library are:
Table One: Value of Time $\$$ per bour
5
10
20
Required Utility
$\$ 4.38$
8.75
17.50

This calculation shows why faculty and working adults do not use libraries as much as librarians would wish. In many cases, the cost of their time is simply too great.

The second variable is the success rate. These results are shown below. Again with the odds 75 percent that the search will take 15 minutes, different values of the user's time are shown. The values given are the utility required for a trip to the library to be worth the time invested.

\begin{tabular}{crrr} 
Table Two: Library & \multicolumn{3}{r}{ Success } \\
\$per bour & $40 \%$ & $50 \%$ & $60 \%$ \\
5 & $\$ 5.47$ & $\$ 4.38$ & $\$ 3.65$ \\
10 & 10.94 & 8.75 & 7.29 \\
20 & 21.88 & 17.50 & 14.58
\end{tabular}

A decline in the success rate from 50 percent to 40 percent increases the cost of using the library by 25 percent. An increase in the rate of success from 50 percent to 60 percent decreases the cost by 20 percent. The higher the success rate, the more likely the library is to be used. The question: Are the costs to improve the success rate worth the investment?

A third variable is the amount of time the user will spend in the library. For example, with an online circulation system the chances are much higher that a user will only spend a short period of time, since it quickly becomes clear whether the book is available or not. When we hold the success rate at 50 percent 
and only change the percentage chance that the search is short - that it will take 15 minutes rather than an hour - the results are shown in Table Three. Again, the various values of the user's time are noted.

A decline in the chance of a short search from 75 percent to 50 percent will increase the utility required to make the trip to the library by 43 percent. If the chance of a short search increases from 75 percent to 90 percent, the required utility drops by 34 percent. If a short search is guaranteed, the utility required to make the trip drops another 30 percent. This gives some insight into the popularity of online circulation systems and provides a clear sense of the costs to the user of the possibility of a long search.

So far in our analysis we have only considered that the user is looking for a known item. The book is either found or not found. There is a third possibility. The user might fail to find the book he or she is looking for, but find another book that is just as good. If we return to our initial assumptions - a 75 percent chance of a short search and a 50 percent success rate - and consider the effects of the odds of finding a substitute for the book being sought, the results are as shown in Table Four.

As the chance of finding a substitute book increases, the utility required to make the trip to the library declines at the same rate. Libraries already spend a considerable amount of time and effort increasing the chances that users will find substitute books. It is clear that these efforts are important in decreasing the utility required to travel to the library and in increasing the likelihood that the library will be used.

A final important factor is the cost of repeated use. Often a book is needed more than once. This may be an important factor in considering alternative approaches to acquiring a title. Table Five shows the utilities required to search for a book twice in the library. They are not merely twice the cost of searching. If the chances of success in any single search are 50 percent, then the chance of finding the book in two successive searches is only 25 percent. The utilities required to attempt two successive searches are shown in Table Five. Different initial success rates and values of time are

Table Three: Chance of Short Search in the Library

$\begin{array}{crrrr}\$ \text { per bour } & 50 \% & 75 \% & 90 \% & 100 \% \\ 5 & \$ 6.25 & \$ 4.38 & \$ 3.25 & \$ 2.50 \\ 10 & 10.50 & 8.75 & 6.50 & 5.00 \\ 20 & 25.00 & 17.50 & 13.00 & 10.00\end{array}$

Table Four: Substitute Books in the Library

$\begin{array}{crrrrr}\text { \$per Hour } & \text { None } & 20 \% & 40 \% & 60 \% & 80 \% \\ 5 & \$ 4.38 & \$ 3.65 & \$ 3.13 & \$ 2.73 & \$ 2.43 \\ 10 & 8.75 & 7.29 & 6.25 & 5.47 & 4.86 \\ 20 & 17.50 & 14.38 & 12.50 & 10.94 & 9.72\end{array}$

Table Five: Cost of Two Library Uses

$\begin{array}{crrr}\text { \$per Hour } & \text { Initial Success Rate } & \\ 5 & 40 \% & 50 \% & 60 \% \\ 10 & \$ 27.34 & \$ 17.50 & \$ 12.15 \\ 20 & 54.69 & 35.00 & 24.31 \\ & 109.37 & 70.00 & 48.61\end{array}$

Table Six: Book Store Success Rates

$\begin{array}{crrrr}\text { \$ per Hour } & 10 \% & 20 \% & 80 \% & 90 \% \\ 5 & \$ 12.50 & \$ 6.25 & \$ 1.56 & \$ 1.39 \\ 10 & 25.00 & 12.50 & 3.13 & 2.78 \\ 20 & 50.00 & 25.00 & 6.25 & 5.56\end{array}$

Table Seven: Substitute Books in Book Stores

$\begin{array}{ccrrrr}\text { \$ per Hour } & \text { None } & 20 \% & 40 \% & 60 \% & 80 \% \\ 5 & \$ 6.25 & \$ 3.47 & \$ 2.40 & \$ 1.84 & \$ 1.49 \\ 10 & 12.50 & 6.94 & 4.81 & 3.68 & 2.98 \\ 20 & 25.00 & 13.89 & 9.62 & 7.35 & 5.95\end{array}$

shown; the chance of a short search is constant at 75 percent.

One way of interpreting these figures is to consider them in light of what you would pay to own the book. It becomes clearer why people will purchase books, even at high prices, when repeated use is required. It also helps explain why photocopying has become a way of life and user frustration with reserve readings is high. The simple fact is that libraries become very expensive to use when multiple uses of a particular book are required.

\section{Book Stores}

After libraries, the second alternative for acquiring a book is to buy it from a book store. The primary limitation of book stores is that even the largest do not stock a high percentage of books in print. No book store will have anywhere near the number of books available in even a small library. This is not as important in our analysis as it might seem. It doesn't matter that a user or customer can't find every book in a store. What matters is whether that customer can find the particular book he or she needs.
To demonstrate this, Table Six shows the utility required for a customer to make the trip to the book store, not including the cost of the book. We will consider two extremes. First, where the customer is looking for a random in-print book and the chances of the book store having it are low; and second, where a bestseller is sought and the chances of the store having it are high. In this analysis we shall assume a short (15minute) search. Remember that the cost of the book is not included.

A book store needs to give its customers a good idea of what they can expect to find. Book stores should project a clear image of what books can be reliably found in the store and consistently deliver these titles. The purchase of a book is very competitive with the use of a library for those titles that are likely to be found in a given store and that cost about $\$ 10$. If the book will be needed more than once, much more expensive books are competitive.

Substitution is the second important concern for book stores. I will often have a particular book in mind when I go to a book store, but would be quite happy to take another title. 
This is especially true if the book is leisure reading. Table Seven considers the utility required to go to the book store, given different levels of substitution. The search time is always 15 minutes and the success rate is 20 percent; the cost of the book is not included.

As we might expect, the greater the chance of finding a substitute the more willing we would be to use the book store as an alternative, even when the chances of finding a specific book are low. Because the time invested in looking is less than in a library, this alternative is competitive with the library for inexpensive $-\$ 2$ to $\$ 5$-books. This is one reason why many people will purchase paperback books rather than use a library, even though the book will only be used once.

\section{Direct Orders}

The third option available to someone wishing to acquire a book is to order the book directly from the publisher. On the plus side, the amount of time required is minimal and the result is generally predictable. The disadvantages of direct orders are that you can not look over the book as you can in a book store or library, and there is generally no opportunity for substitution.

The minimum amount of time in- volved is shown in Table Eight. Here we assume that there is a 90 percent chance that the order will be successful and that the time invested is 15 minutes.

$\begin{array}{cc}\text { Table Eight: Cost of Direct Order } \\ \$ \text { per Hour } & \text { Cost per Order } \\ 5 & \$ 1.39 \\ 10 & 2.78 \\ 20 & 5.56\end{array}$

Books that cost under $\$ 10$ are competitive with library usage. Where multiple use is expected, the competitive advantage is even greater.

The real disadvantage of direct order is that the book may not turn out to be what is expected. This is the chance taken in ordering a book without looking it over first. Table Nine considers this; here we show the utility required to order a $\$ 10$ book when the chance of receiving it is 90 percent.

As the likelihood that the book will live up to expectations declines, the utility required to submit the order increases. But even so, direct ordering a $\$ 10$ book remains competitive with many library and book store options. Nonetheless, it is important for a publisher trying to generate direct sales to give the customer what he or she expects. When the book

Table Nine: Chance Book Will Be as Ordered

$\begin{array}{crrr}\$ \text { per Hour } & 100 \% & 90 \% & 80 \% \\ 5 & \$ 11.39 & \$ 12.66 & \$ 14.24 \\ 10 & 12.78 & 14.20 & 15.98 \\ 20 & 15.56 & 17.29 & 19.45\end{array}$

$60 \%$

$\$ 18.98$

21.30

29.53

Table Ten: Summary of Options Library

$75 \%$ short search, $50 \%$ success

No substitution

$90 \%$ short search, $50 \%$ success No substitution

$75 \%$ short search, $50 \%$ success $40 \%$ substitution

$75 \%$ short search, $50 \%$ success

Two uses

$\begin{array}{ccc}5 & 10 & 20 \\ \$ 4.38 & \$ 8.75 & \$ 17.50 \\ 3.25 & 6.50 & 13.00 \\ 3.13 & 6.25 & 12.50 \\ 17.50 & 35.00 & 70.00\end{array}$

Book Store

$20 \%$ success, No substitution

$\$ 10$ book price

$80 \%$ success, No substitution

$\$ 10$ book price

$20 \%$ success, $40 \%$ substitution

$\$ 10$ book price

$\begin{array}{lll}16.25 & 22.50 & 35.00 \\ 11.56 & 13.13 & 16.25 \\ 12.40 & 14.81 & 19.62\end{array}$

Direct Order

$90 \%$ book is what is expected $90 \%$ success, $\$ 10$ book price $\begin{array}{lll}12.66 & 14.20 \quad 17.29\end{array}$ is one he or she especially wants, this option is then the most desirable.

\section{Time is Money}

Some options and utilities are shown in Table Ten. Looking at this summary, it becomes clear that all library options are costly for someone whose time is worth $\$ 20$ per hour. For such people, book store options are competitive, as is direct order. For people whose time is less valuable, the library is generally the most competitive option. The significant exception to this rule is that whenever multiple use is required the library becomes prohibitive. Purchase of books priced over $\$ 15$ is a better option, even for people with time valued at only $\$ 5$ per hour. This helps explain why students will photocopy almost anything they have to read on reserve. It also suggests that the creation and sale of anthologies as an alternative to reserve operations would be competitive even when costs for the anthologies are quite high.

This study shows that book stores are the most competitive alternatives when they can deliver items the customer expects to find or when there is a high probability that the customer will accept a substitute book. If customers are looking for a specific book and are uncertain whether the store will have it, they must anticipate a high utility before they will go to the book store.

Direct ordering presents an interesting alternative. It is a competitive option if the customer's time is valuable, even if the book does not live up to expectations. When multiple uses of the book are expected, the attractiveness of this option increases. This suggests that publishers should make direct order widely known and as easy as possible to use. Whatever publishers can do to make sure a book meets customer expectations will improve the competitiveness of direct ordering in the long run. The advantages here are that it saves time and the result is certain. This is rarely true when someone goes to a library or book store.

Finally, it is important that librarians, book sellers, and publishers understand that the current distribution systems impose considerable costs on those who wish to acquire books, and that these costs have a significant effect on whether individuals use their services. 